Chapter 9

\title{
Climate Change and Food Security
}

\author{
Christopher Kipkoech Saina, \\ Daniel Kipkosgei Murgor and Florence A.C Murgor
}

Additional information is available at the end of the chapter

http://dx.doi.org/10.5772/55206

\section{Introduction}

Climate change is possibly the most significant environmental challenge of our time and poses serious threats to sustainable development in the world and more so in most developing nations. Impact of climate change affects ecosystems, water resources, food and health. As such inter-related government policies must be designed to avoid conflicts in policy design and implementation. There is a direct link between climatic changes and global food insecurity more so in developing countries where climate change compounded with poverty has exacerbated the impacts. In order to address the challenges posed by climate change, it is necessary to examine the factors contributing to climate change and how such influence food production globally. Climatic factors like precipitation, evaporation, humidity and sunshine duration form the basis for improvement of food security. There is need for policy makers, communities and aid providers to incorporate evidence based technologies in food systems and knowledge. Evidence based technologies are those that have empirically been tested and used. They include zero tillage, integrated soil fertility management; irrigation technologies for example drip irrigation, seed improvement, water harvesting, organic agriculture and incorporation of indigenous knowledge. The impact of some of the technologies can be seen in the light of global improved grain yield through use of integrated soil fertility management, rain-fed and irrigated environment technologies. Drought-tolerant grain crops are also likely to help increase yields.

The results of this study are pertinent to policy makers in the field of food security and livelihood sustainability. Mitigation and adaptation measures must be effective, affordable and appropriate for environmental sustainability and development. This review advocates for the integration of conventional agro-science based systems with traditional agricultural 
knowledge in order to mitigate the severity of climate change and its impact on food security and livelihoods sustainability. Integration of agro-science and traditional agricultural systems is important if food security is to be sustained.

\section{Global climate change}

The expression of the term "climate change" according to many people means the alteration of the world's climate as a result of human activities through fossil fuel burning, clearing forests and other practices that increase the concentration of greenhouse gases (GHG) in the atmosphere. This is in line with the official definition by the United Nations Framework Convention on Climate Change that states that climate change is the change that can be attributed "directly or indirectly to human activity that alters the composition of the global atmosphere and which is in addition to natural climate variability observed over comparable time periods" [1]. The Intergovernmental Panel on Climate Change (IPCC) defines "climate change" as "a change in the state of the climate that can be identified by changes in the mean and or the variability of its properties, and that persists for an extended period, typically decades or longer" [2]. Climate change can be defined as a systematic change in the key dimensions of climate including average temperature and wind and rainfall patterns over a longer period of time. In recent usage, especially in the context of environmental policy, climate change usually refers to changes in modern climate. It may be qualified as anthropogenic climate change, more generally known as "global warming" or "anthropogenic global warming" (AGW).

\section{Impact of climate change}

Due to prevailing nature of enhanced greenhouse effect in the atmosphere, the following effects have occurred at the global, regional and national levels.

Based on [3]; [4], there has been evidence of increase in global temperatures that has led to climate change at global, regional and national levels over the past 100 years. Increase in global temperatures experienced over the past century is as a result of accumulation of greenhouse gases in the atmosphere leading to global warming. Using complex climate models, the "Intergovernmental Panel on Climate Change" in their third assessment report has forecast that global mean surface temperature will rise by $1.4^{\circ} \mathrm{C}$ to $5.8^{\circ} \mathrm{C}$ by the end of 2100 . Multiple datasets show essentially the same global warming trend over the past 100 years, with the steepest increase in warming in recent decades. The evidence of human-induced climate change goes beyond observed increases in average surface temperatures; it includes melting ice in the Arctic, melting glaciers around the world, increasing ocean temperatures, rising sea levels, acidification of the oceans due to excess carbon dioxide, changing precipitation patterns, and changing patterns of ecosystem and wildlife functions. Reduced agricultural productivity 
with the resultant food shortages has been experienced. Studies have shown that with higher concentrations of $\mathrm{CO}_{2}$, plants can grow bigger and faster. However, the effect of global warming may affect the atmospheric general circulation and thus altering the global precipitation pattern as well as changing the soil moisture contents over various continents.

- There has been an increase in sea level observed in some parts of the world due to excess heating of air - which has caused large scale melting of ice covers. Large scale flooding of California in 1999 and parts of western coast in India in the last 5-8 years are testimonies to effects of sea level rise. If the sea level rises by $80-90 \mathrm{~cm}$, perhaps many of coastal cities of the world will be washed away besides great changes in harbours and their facilities, in sea routes and in fishery industry [3]. Loss of fertile agricultural land occasioned by flooding impacts on food security and livelihoods at household and national level. There has been an increase in drought and floods globally. Ironically, changes in the climate due to excess greenhouse gases are causing both increased drought and increased flooding. Violent storm activity increase as temperatures rise and more water evaporates from the oceans. This includes occurrence of more powerful hurricanes, pacific typhoons, and an increased frequency of severe localized storms and tornadoes. These storms often result in flooding and farmland damage hence causing food insecurity. Warming also causes faster evaporation on land leading to drought induced famine.

- Change/shifts in seasons and seasonal characters have been experienced through out the globe due to change in air temperature and rainfall patterns. Some seasons have either been shortened or prolonged. Winters have extended in many places, while summer is more severe in other places. The degree of dependability has reduced and an element of uncertainty has increased. This disorientates the farmers in the rural community who have hitherto depended on indigenous knowledge in predicting weather patterns in food production.

- Major changes have occurred in water resources of the world due to disturbances in hydrological cycles. Heavy rainfall tracts are gradually converted into low rainfall tracts with many humid areas being transformed into arid areas. Similarly, ground water depletion is high and recharging is very low.

- There has been a shift in disease/pest cycles of plants and animals. Many insignificant pests / diseases are attaining major proportions because composition of microbial population is affected by shift in temperature and hydrological cycles. These have impacted on food production output and post harvest loss occasioning food shortages and loss of livelihoods.

- Ecosystems change. Changes in climate will cause some species to shift from one region to another and in combination with other stresses such as development, habitat fragmentation, invasive species, could have negative consequences on biodiversity and the benefits that healthy ecosystems provide to humans and the environment. Water hyacinth, an invasive species in Lake Victoria has tremendously reduced fishing activities impacting on livelihoods. 

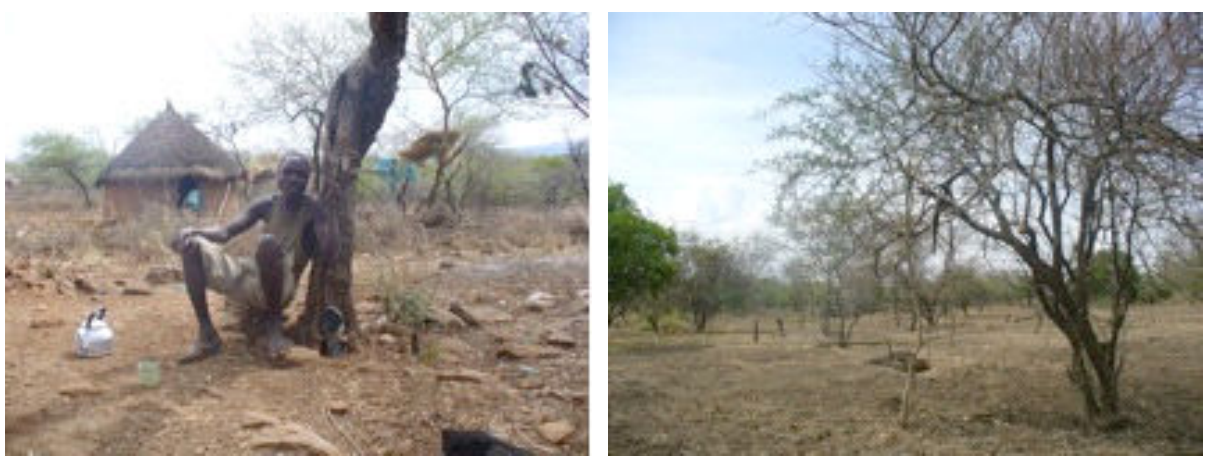

Figure 1. Depicts typical ravages of climate change in Kerio Valley, Kenya May 2012

\section{How climate change will affect livelihoods}

The economy and environment could be affected as a result of climate change especially in the absence of countermeasures. The following are some of the livelihood sectors that are likely to face some impacts according to [5] and other literature:-

The health sector impacts will affect the populations by altering the health status of millions of people, including through increased deaths, disease and injury due to heat waves, floods, storms, fires and droughts. Increased malnutrition, environmentally related diseases such as cholera, dysentery, meningitis, lymphatic filariasis, yellow fever, malaria, TB among others in some areas will exert great pressure on the public health resources and development goals will be threatened by longer-term damage to health systems from disasters.

In the water sector, it is predicted that climate change will lead to an intensification of the global hydrological cycle hence having an impact on water resources. A change in both volume and distribution of water will affect both ground and surface water supply for industrial and domestic uses, irrigation, hydropower generation, navigation, in stream ecosystem and water based recreation. Drought-affected areas will likely become more widely distributed. In the event of drought in Arid and Semi arid environments sensitive to slight changes in climate, there is bound to be human - human and human - wildlife conflict with respect to use of the scarce resources. Heavier precipitation events are very likely to increase in frequency leading to higher flood risks. By mid-century, water availability will likely decrease in mid-latitudes, in the dry tropics and in other regions supplied by melt water from mountain ranges. More than one sixth of the world's population is currently dependent on melt water from mountain ranges. 


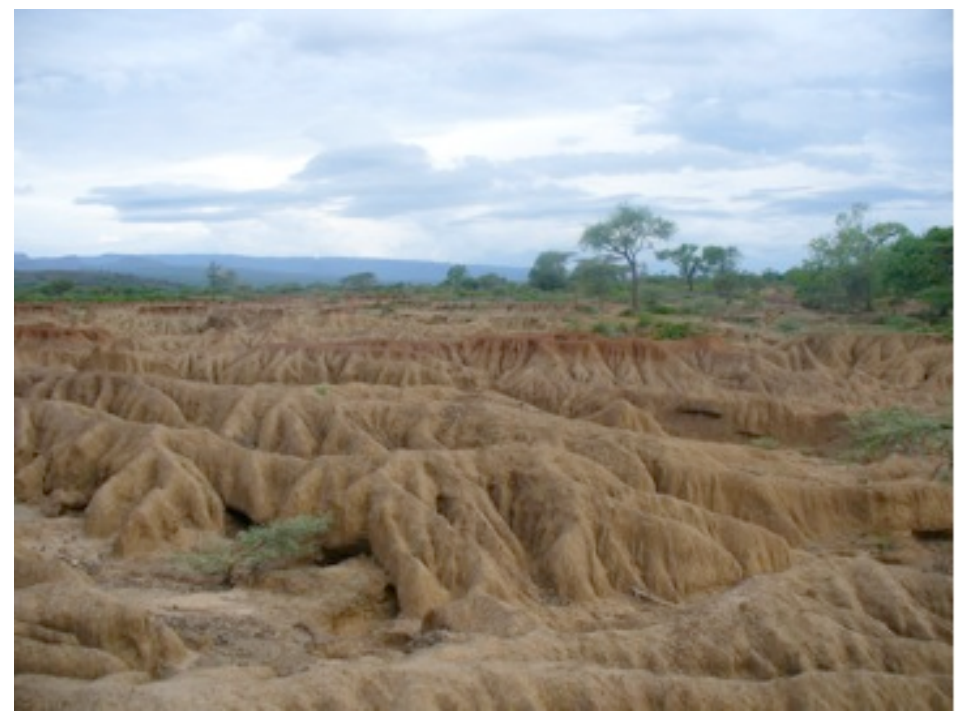

Figure 2. Fragile ecosystems are destroyed during heavy rainfall; a consequence of climate variability. Kerio Valley, Kenya, May 2012.

Biodiversity and biomass energy will be affected by climate change by affecting both plants and animals distribution, population sizes, physical structure, metabolism and behaviour. Climate induced changes will largely influence the distribution of tree parasites and pathogens which will ultimately play an important role in determining future tree distribution. Climate change alters conditions in ecosystem making species unable to cope with sudden changes. There has been direct and indirect impact on the forest ecosystem. The direct impacts result in water stress in plants due to prolonged dry spell. This in turn increases fire hazards in forest areas. The biomass energy sub sector is sensitive to climate variability as productivity is a function of rainfall and temperature. Increased temperatures leads to drying of biomass hence declining biomass productivity like decreased fuel wood supply. Globally, most households rely on wood fuel for the cooking and heating especially in sub-Saharan Africa thus endangering livelihoods and environmental sustainability.

Agriculture/Food sector will see those mid-latitude and high-latitude areas initially benefit from higher agricultural production and many others at lower latitudes, especially in seasonally dry and tropical regions. The increases in temperature and the frequency of droughts and floods are likely to affect crop production negatively, which could increase the number of people at risk from hunger and increased levels of displacement and migration in search of livelihoods.

Human settlement and business are the most vulnerable especially those located in coastal areas and river flood plains, and those whose economies are closely linked with climate-sensitive resources. This applies particularly to locations already prone to extreme weather events, and especially areas undergoing rapid urbanization. Where extreme weather events become more 
intense or more frequent, the economic and social costs of those events will increase. Cities loom as giant potential flood or other disaster traps.

Livestock sector is affected by climate changes by interfering with the distribution, production size and frequency of disease and pests. Livestock industry depends on the balance of pasturage and water resources supply and any form of change in climate will impact negatively the livestock sector. The impacts have largely been felt by pastoralist communities who have been forced to change their livelihood from pastoralists to sedentary agro pastoralist to survive.

Climate causes instability in the tourism sector for those countries whose economies are largely dependent on tourism. Addition or reduction in precipitation leads to wildlife devastation and reduces the aesthetic value of sceneries hence impacting on livelihoods dependent on the industry.

Gender is similarly impacted by climate change. The gender poverty link show that $70 \%$ of the poor in the world are women and their vulnerability is accentuated by race, ethnicity and age. Most climate change policies, issues and programs are not quite gender neutral despite the fact that women and men are affected differently due to tradition, socially constructed roles and responsibilities.

\section{Climate change mitigation and adaptation measures}

Mitigation is "an anthropogenic intervention to reduce the anthropogenic forcing of the climate system; it includes strategies to reduce greenhouse gas sources and emissions and enhancing greenhouse gas sinks [1]. To ensure that environmental sustainability is maintained some urgent measures need to be put in place to help in sustainability of the environment by way of mitigation. Some examples of mitigation actions include developing new low-energy technologies for industry and transport, reducing consumption of energy-intensive products and switching to renewable forms of energy such as solar and wind power. Natural carbon sinks, such as forests, vegetation and soils, can be managed to absorb carbon dioxide, and technologies are being developed to capture carbon dioxide at industrial sources and to inject it into permanent storage deep underground. There is need also to manage the impact as have occurred on the environment. It is true that future impacts on the environment and society are now inevitable, owing to the amount of greenhouse gases already in the atmosphere from past decades of industrial and other human activity and to the added amounts from continued emissions over the next few decades until such time as mitigation policies become effective. Taking steps to cope with the changed climate conditions is called "adaptation".

Adaptation is "the adjustment in natural or human systems in response to actual or expected climatic stimuli or their effects, which moderates harm or exploits beneficial opportunities" [6]. The measures to be undertaken are those that will try to address the adverse impacts that may occur as a result of non action by humans with the aim of attaining a sustainable environment. Some of these measures may include some of the following; conducting risk assessments, 
protecting ecosystems, improving agricultural methods, managing water resources, building settlements in safe zones, developing early warning systems, instituting better building designs, improving insurance coverage, developing social safety nets and enhancing public awareness and education. All these measures are intrinsically linked to sustainable development as they reduce the risk to lives and livelihoods and increase the resilience of communities to all hazards. Both, adaptation and mitigation should be considered jointly, as some adaptation measures can contribute to reducing greenhouse gas emissions, while conversely mitigation measures can be planned to help reduce the impacts.

\section{Global food security}

Food security exists when all people at all times have physical or economic access to sufficient safe and nutritious food to meet their dietary needs [7]. Global food security refers to the situation where each person, member of any household is having physical and economic access to sufficient, safe and nutritious food to meet their dietary needs and food preferences for an active and healthy life - (Food and Agriculture Organization definition). That food has to be affordable, safe and healthy, culturally acceptable, meeting specific dietary needs of the people and is obtained in a dignified manner, produced in ways that are environmentally sound and socially just. Thus there should be no perceived inadequacy of the household food supply expressed through concerns about running out of food and not having enough food to make a meal or malnourished as a result of physical unavailability of food, lack of socio-economic access to food or inadequate food utilization.

The World's efforts to meet the Millennium Development Goal of cutting hunger in half by 2015 are far from reach. With the world's population set to reach 9 billion by 2050, agricultural production will need to increase by $70 \%$ in order to meet demand. Climate change adds a new dimension of this challenge as it is one of the key drivers of change affecting the food system and contributing to rising food prices. It leads to changes in growing seasons and rainfall patterns and the increased frequency of extreme events such as droughts and floods. It has been estimated by the United Nations Environment Programme that up to 25 per cent of world food production could be lost by 2050 as a result of climate change, water scarcity and land degradation [8].

In the developing world, nearly 1 billion people are unable to meet their dietary needs. Another $5-10 \%$ is at risk of 'acute' food insecurity in times of crisis. Despite improvements, the millennium development goal on hunger is likely to be missed by a wide margin in areas like SubSaharan Africa, where persistent food insecurity is compounded by widespread political instability, conflict and the HIV/AIDS pandemic. The UN Food and Agriculture Organization [9] estimate that 820 million people in developing countries are suffering from malnutrition. In a world in which nearly half the population survives on $\$ 2 /$ day or less, more than 800 million people go to sleep hungry any given night, and a child dies every five seconds due to hungerrelated complications, the need to respond to the needs of the poor for food is ever-present and widespread. Despite the universal recognition of every person's right to food, vulnerability to hunger remains a daily reality for many [10]. 
The United States of America and European Union together provide about two thirds of global food aid deliveries. The United States of America is by far the most important donor of food aid both for bilateral programme aid and as the main contributor to the World Food Program. The World Food Program (WFP) is the primary agency responsible for administering multilateral food aid. The WFP and various NGOs administer project food aid to support a wide range of developmental projects targeting the poor in developing countries. Others include the UN Food and Agriculture Organization (FAO), the Food Aid Convention (FAC) and the World Trade Organization (WTO). All these organizations have different mandates and are concerned with different aspects of the provision of food aid. Many organizations around the world are working to find ways to produce the food needed in a sustainable way, within the limits of what our ecosystems can support for current and future generations, and to safeguard this production from the impacts of climate change. Food security is the outcome of food system processes all along the food chain. Climate change will affect food security through its impacts on all components of global, national and local food systems. It is important to note that climate change variables influence biophysical factors, such as plant and animal growth, water cycles, biodiversity and nutrient cycling, and the ways in which these are managed. Agriculture is the primary source of livelihood among many rural populations [11].

\section{Causes of global food insecurity}

There are many causes of global food insecurity and most of them are region specific, except climate change where impacts are felt globally. Some are human causes like destruction of fertile lands and others are non-human like natural disasters (e.g. floods). While human destruction of his mother nature through careless management practices have impacted negatively on his ability to produce enough food for the population, the contribution that humans make to climate change is potentially causing increased food insecurity globally. Industrialization, modern agricultural practices and the need to produce for the market without thinking about environmental sustainability has had disastrous effect as climate change has set in. In some areas, sea levels have risen and increased incidence of extreme events posing danger and threatening livelihoods and at the same time increasing the vulnerability to future food insecurity in the world. Coastal freshwater are being contaminated with salt water and people do not get fresh water for domestic use and plants or food crops that are not salt-tolerant cannot be grown. Storm surges become common occurrences together with flooding. This hinders people living along coast from growing food crops. Increased temperature also leads to heat stress for plants which increase evaporation and lowers productivity. Climate change has also been a cause of more frequent and more intense extreme weather events like increasing irregularities in seasonal rainfall patterns. The changing growing seasons have shifted ecological niches.

Rainfall is becoming more unpredictable and unreliable and has become a common occurrence leading to greater uncertainty among farmers and their traditional agricultural knowledge and coping strategies. The phenomenon has had immediate impact on food production, distribution, infrastructure, livelihoods and human health in all parts of the world. Where climate 
change has influenced rainfall and temperature patterns, the suitability of land for different types of crops and pasture is affected, including the health and productivity of forests; the distribution, productivity and community composition of marine resources and the increased incidence of pests and diseases. It also affects the functioning of biodiversity and ecosystem of natural habitats; and the availability of good-quality water for crops, livestock and inland fish production. It may also increase aridity of arable lands, induce drought and deforestation, can increase fire danger with consequent loss of the vegetative cover needed for grazing and fuel wood [12]. It also leads to depletion groundwater and induce the internal and international migration thereby triggering resource-based conflicts and civil unrest in either areas of origin or destination. Conflicts over water resources will have implications for both food production and people's access to food in conflict zones [13]. Production from both rain-fed and irrigated agriculture in dry land ecosystems accounts for approximately 25 percent, and rice produced in coastal ecosystems for about 12 percent [14].

Natural fall-back mechanisms during food crisis may also be affected. These include disappearance of traditional fruits, herbs, vegetables, mushrooms, wild foods and other coping mechanisms. It is expected that as the world climate continues to change, 5000 plant species in sub-Saharan Africa will decrease in size or shift to other agro-ecological zones due to climate change (Levin and Pershing, 2005). All these impacts have negative influence on food security of the people living in the affected areas. At the same time people may resort to unfamiliar ways of surviving and countering food insecurity. It was observed that people may decide not to migrate but find new, unfamiliar ways of earning a living [15]. FAO has been instrumental in assisting various communities all over the World develop the right food production technologies aimed at boosting food security. They possesses technical expertise relevant to climate change adaptation in a variety of ecosystems, including agro-ecosystems (crops, livestock, grasslands), forests and woodlands, inland waters, and coastal and marine ecosystems. It works to build national, local and community-level capacities to raise awareness of and prepare for climate change impacts, assists member countries in identifying potential adaptation options and helps local people understand which are the most applicable to their particular circumstances.

Since 2002, FAO has been promoting National and Regional Programmes for Food Security (NPFS and RPFS) as instruments that help countries enhance productivity and diversify the livelihoods of rural people on a scale sufficient to achieve the 2015 targets set by WFS and the Millennium Development Goals (MDGs). This is an organization committed to eliminating food insecurity in the World. From their advice, people have created artificial microclimates, breed plants and animals with desired characteristics, enhance soil quality, and control the flow of water. Advances in storage, preservation and transport technologies have made food processing and packaging a new area of economic activity. This has allowed food distributors and retailers to develop long-distance marketing chains that move produce and packaged food. The countries that are not able to adopt new technologies need to be assisted. Developing countries urgently need more assistance to help them prepare for the impacts of climate change that are unavoidable. The transfer of the industrialised countries' best energy efficiency and renewable energy technology and assistance with disaster preparedness, agricultural produc- 
tivity improvements, water management, conflict prevention, reforestation, preventing deforestation and critical infrastructure would be most appropriate.

Other important practices for addressing food insecurity include changing consumption patterns and food preparation practices, efficient water use, improving soil quality, capacity to withstand extreme events and carbon sequestration. Others include promotion of agro biodiversity for local adaptation and resilience, reducing uncertainty by improving the information base and devising innovative schemes for insuring against climate change hazards.

People need to adopt practices that enable the vulnerable to protect their existing livelihood systems, diversify their sources of income, change their livelihood strategies or migrate. Sustainable livestock management practices for adaptation and associated mitigation should also be given high priority.

\section{Integrating indigenous knowledge and science based technologies}

Integration of both indigenous knowledge and science based technologies is important in combating the effects of climate change on food security. Farmers need to combine the best of their traditional approaches with modern agro-science based technology. Towards this end documenting traditional knowledge of the world is paramount if an integrated approach is to be effective as most traditional knowledge remains as tacit knowledge.

\section{Indigenous food systems}

Communities have created and developed unique food systems over time in their specific local ecosystems. Communities have used these technologies for a long period of time and have perfected them to improve their livelihoods. Traditional knowledge in the management of agriculture and food production is important. Indigenous people in Sub-Sahara Africa have developed methods of surviving droughts and emergency. However, aid providers have ignored this vital knowledge inherent in the local people during their programme intervention. According to [16], one of the most important methods in combating desertification is the recognition of the value of traditional knowledge in drought management.

Severe changes in global climate are projected to affect livelihoods systems and consequently food security. Droughts and floods have become frequent, occasioning loss of livelihoods migration and insecurity. Compounding the vagaries of climate change is the upward trends of population increase. These are often marginalized, poverty stricken persons. Poverty poses a serious environmental threat as people exploit natural resources with inappropriate technology in order to survive. Population increase occasions agricultural practice in marginal lands. This causes resource degradation and environmental degradation leading to poor harvest and food insecurity. Indigenous food system knowledge is required to reduce the 
effects of soil erosion leading to poor food production. Family and tribal structures and their autonomous traditional practices of resource management and land tenure have broken down. Therefore, traditional land tenure systems and agricultural practice of improved shifting cultivation should be incorporated into policy. This is because community elders control parcels of land to be used for food production and grazing. Grass stripes are used as a form of land management in Swaziland and grazing rotation by Lake Victoria communities thus, soil erosion and biodiversity loss is checked [17].

Drought influences availability of water for crop production. This is projected to be a major constrain to food security, and economic development in the future. In Africa climate change is expected to intensify the continents critical food situation. Reduction of water quality and availability will increase food insecurity [18]. Governments must therefore fund research on crops that require less rain, are faster in maturity and pest resistant. These are the almost extinct traditional indigenous food crops. This is corroborated by the UN/ISDR 2007. Governments' agricultural policies must allow for diversification of food crops to cushion populations against loss of livelihoods in the face of climate variability. Increased production in traditional root crops and food legumes and lentils for sustainable agriculture and food security must be incorporated into agricultural policies. Production of food grain or root crops must be increased to decrease dependency on food export in Africa. Similarly, value chain actors that include suppliers, farmers, traders and processors must be strengthened in the sector of food production. This calls for the cultivation of more indigenous food crops to reduce aid dependency. Incorporating modern food production methods with indigenous food systems is ideal as people are better able to adopt new ideas when these can be seen in the context of existing practices.

Indigenous systems of crop protection against pests must be integrated into agricultural policy. This is cheap and more available system to the rural poor farmer. The wide spread use of indigenous material, such as agrochemical plants to combat pests that normally attack food crops has been reported. It is likely that climate change will alter the ecology of disease vectors and as such indigenous practices of pest management would be useful for adaptation strategies. Other indigenous systems that are adopted by local farmers include controlled bush clearing. Smoking of seeds to deter stock borers, use of green manure and green mulch spray as herbicide, all improve food production and reduces the vagaries of food insecurity. Pastoralists in Arid and Semi Arid Lands (ASAL) in Africa use a multi-species composition of herds to survive climate extremes. Traditionally they forego large grazers for small browsers like goats and sheep since the feeding pattern of the latter is lower [19].

Men and women play different roles at the household and community levels, climate change affects women disproportionately than men. Women interact with nature more but have limited mitigating and adaptive capacities. Climate change and variability are therefore likely to amplify existing patterns of disadvantage. Women in Africa are custodians of culture and customs. This vast knowledge must be used to mitigate climate change and food insecurity. Women workload in rural Africa is always based on the maintenance of household food security particularly in hardship seasons [20]. It is through this role that while modernizing policies in food production, we must adjust male bias to avoid falling into the trap of food 
insecurity. Women must have access to land titles, inputs and credits and must be deliberately involved in agricultural extension [21]. Inclusive policy will design and implement programmes that lead to gender equity and food security.
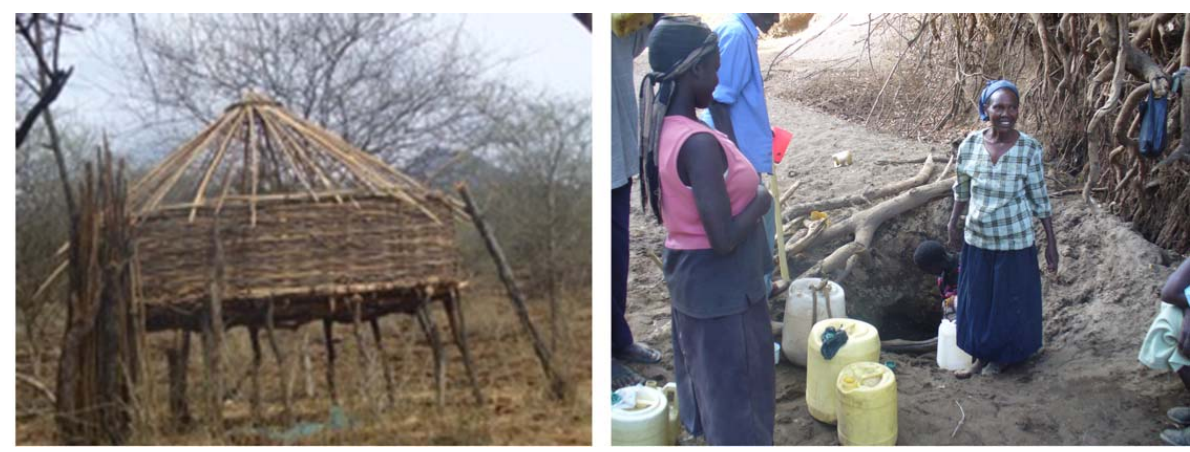

Figure 3. The photos depict impact of climate change and livelihood coping strategies. The photographs were taken the arid areas of Kerio Valley, Kenya May 2012.

Poverty driven environmental degradation has been exacerbated by the erosion of tradition knowledge by westernization. Traditionally, cultural norms and practices and taboos were used to regulate and ensure sustainable exploitation. Poverty drives communities to farm in marginal fragile ecosystems, using rudimentary technology leading to environmental degradation, poor yields and hence food insecurity. It is therefore considerable to conclude that the spiral events of poverty, poor technology, lack of inputs and land tenure culminate in unsustainable underdevelopment. Governments must therefore invest in their populations to eradicate poverty, thus providing a springboard to address food security for sustainable development. A healthy citizen is in a position to adapt new technology and address environmental challenges of climate change.

\section{The role of technology in food security}

With the world population expected to reach over 9 billion by 2050, the global demand for food is projected to increase by at least 2.5 times over current levels [22]. The challenges of feeding over 9 billion people by 2050 in a sustainable and environmentally friendly way cannot be met without the continued innovation and adoption of new technologies. To achieve notable increases in agricultural productivity, technology and innovations must be applied to the entire agricultural supply chain. From notable advances in biotechnology that can make more efficient use of water and fertilizers and reduce pesticides, to bio-fortification, improved crop varieties and best practices to reduce post-harvest losses and improve irrigation methods, a science-based approach to new and existing technologies must be applied to maximize their potential benefits worldwide. These technologies, along with traditional breeding approaches, are all essential to meeting the demands being placed on agricultural productivity [22]. 
Throughout the last century, the potential increase in agricultural productivity has been achieved by adopting and applying innovative agricultural technologies worldwide. These increases have not only bolstered food security, but have helped minimize the environmental impacts of agriculture. This is critical, because loss of biodiversity and habitat in turn lead to desertification, loss of fresh water sources, and greater food insecurity. Major innovations in mechanization, the use of fertilizers and pesticides, and plant and animal management and breeding techniques provided the basis for the fivefold increase in US agricultural output over the twentieth century. This increase in output was achieved with less land and labour, and in recent years with less energy and chemical use per unit of output [23].

In many parts of the world - particularly South and East Asia - growth in agricultural productivity has been rapid, largely as a result of the extensive adoption of new agricultural technologies. For millions of poor people, particularly in Asia, the technological advances of the Green Revolution (complemented by a massive increase in irrigation) provided a route out of poverty through: directly increasing producer incomes and wages; lowering the price of food; and generating new livelihood opportunities as success in agriculture provided the basis for economic diversification. Asian industrialization was in essence agriculturally led [24]. Despite decades of investment in new agricultural technology however, hunger and poverty continue to plague large areas of the developing world. The problem is particularly acute in areas of the world dependent upon rain-fed agriculture, in particular sub-Saharan Africa, where the impact of new technologies has been less apparent and agricultural productivity has at best stagnated, and may even have fallen in some areas.

\section{Indigenous technology}

According to [25], traditional agricultural practices in Africa provide valuable lessons to be learned from local farmers who, through their own innovations and experimentation on farms, have perfected tools such as the hoe and the plough, developed seeds and plants through preservation and selection, and designed crop mixtures and rotations leading to improved productivity. Practices like fallow, terracing, ridging mixed farming, and intercropping were practiced by local people long before the introduction of the Green Revolution. These practices provide advantages that have been identified as those that have ensured soil fertility, controlled pests as well as diversifying sources. Some examples of traditional technology method that have helped guard against food insecurity at household and national level and helped in the sustenance of the environment include but not limited to the following:-

\subsection{Farmer's seed saving strategy and water harvesting}

For seeds to be of quality and viable in relation to its germination rate, storage and drying are of great importance. One of the common ways of ensuring the dryness of grains even in rainy season is simply to hang on the maize cobs on the ceiling above the cooking fire. Similarly, rain water harvesting through collection pond, irrigation during the evening, water erosion control through plantation, canalling of water through the hard rock area by using wooden 
conduits, aquifer recharging, etc. are some examples of farmers innovations to ensure sustenance of the food production.

\subsection{Solar drying}

Rural communities in Africa and south East Asia have used solar to dry their foods as a form of preservation to bolster food security at the home. Fresh vegetables are immersed in salted boiling water for a few minutes and then dry them in the sun for about 3 days. Similarly, edible insects such as white ants, termites, and caterpillars, mushrooms and tomatoes are stored in the same way. According to [7], drying is also often used to preserve meat, fish, and roots. Cassava and bananas are also preserved by fermentation followed by drying. The drying helps prevent growth of the microorganisms and stops biochemical activities that cause foods to decay. This helps in nutrition and energy needs when fresh supplies are not accessible.

\subsection{Storage of roots and tubers}

Fresh roots and tubers are highly perishable and cannot be stored for long periods thus Cassava has to be processed within 2 days of harvesting to avoid damage. Fresh cassava, therefore, is best left unharnessed until needed. As an alternative, yams, coco yams, and cassava may be stored in underground pits after harvesting. In some instances, root crops such as cassava can be grown as a food reserve, left in the ground for up to 2 years and used as the main source of energy during lean times [26].

\subsection{Hunting and gathering}

This is a food procuring method used by many communities in their quest to meet their food demands. The whole exercise was done in a sustainable manner so that there is more left for the next season. Hunting was controlled to also maintain the ecosystem. Great care was taken not to kill unnecessarily.

\subsection{Fermentation process}

In most Africa countries, fermentation is a traditional method of preserving vegetable surpluses which, when used, enhances the overall flavor of the meal. The technique provides a suitable environment for lactic acid bacteria to grow, thus imparting an acid flavor to the vegetable. Cassava and sweet potatoes are the most commonly fermented foods. Alcoholic beverages constitute the largest category of fermented products in Africa [27]. Most of these beverages are processed from fruits. Banana beer, a popular drink in Eastern and Western Africa region is made by allowing banana juice to ferment. Palm and coconut wine are manufactured in the same way.

\subsection{Home garden}

Home or family garden normally run by the women play a great role in increasing small-scale production of micronutrient-rich foods. The home garden is the most direct means of supplying families with most of the non-staple foods they need year-round. These gardens have saved 
many families from glaring hunger because being small, they are usually planted early hence the crops ripen at the very time of need though in small quantities

Nevertheless, indigenous technology can be integrated with modern technology to come up with appropriate technologies for communities. Such technology developed with indigenous peoples input is easily adopted, less costly and uses available local knowledge. The Marakwet people of Kenya have had traditional furrow systems that they have been using for irrigation and these systems have been integrated with modern systems for best results.

\section{Modern technology}

There is need to adapt science-based technological innovations that are affordable and have positive improvement on global food security and have no or insignificant impact on climate and environmental sustainability. The use of modern technologies to boost food production and thus sustain the global population requires political will and sufficient investments in modern agriculture. In the 21st century, many determinants of food security are transboundary and multilateral agreements towards this cause, are paramount. Appropriate technological innovations are required and be implemented at all levels.

The Green Revolution drove widespread shifts in the agricultural sector from subsistence and low external input agriculture to mono-cropping with high yielding varieties. By the 1970s, Green Revolution-style farming had replaced the traditional farming practices of millions of developing country farmers. By the 1990s, almost $75 \%$ of Asian rice areas were sown with these new varieties. Overall, it is estimated that $40 \%$ of all farmers in developing countries were using Green Revolution seeds by this time, with the greatest use found in Asia, followed by Latin America [28]. The rapid spread of Green Revolution agriculture throughout most countries of the South was accompanied by a rapid rise in pesticide use [28]. This was because the High Yielding Varieties were more susceptible to pest outbreaks. Promising increases of yield were thus offset by rising costs associated with increased use of chemical inputs. Modern agriculture practices, such as precision farming, would help convert this concept of "evergreen agriculture revolution" into a reality. There is need to provide modern agriculture implements at reasonable costs, high-tech agriculture knowledge, agronomic support and agriculture extension services and help with farm planning and crop management, allowing farmers to increase their food output and net incomes in the world. Technological advancement and adaptation is vital for food security.

Sustainable development requires that technologies developed to improve food security situation in the world have least negative impact on the environment while maximizing benefits of improved food production and welfare of humans. There is need to focus on the effect of climate change on domestic production in food-insecure countries, assess climate change impacts on foreign exchange earnings, determine the ability of food surplus countries to increase their commercial exports or food aid and analyze how the incomes of the poor will be affected by climate change. 
Synthetic fertilizers, pesticides and herbicides are made from non-renewable raw materials such as mineral oil and natural gas or from minerals that are depleting such as phosphate and potassium. As the price of petroleum increases, so does the cost of external inputs and machinery, forcing small farmers who are dependent on these inputs into debt. The production of agrochemicals is also an important source of greenhouse gas (GHG) emissions. In particular, fertilizer production is energy intensive, accounting for $0.6-1.2 \%$ of the world's total GHGs [29]. Industrial, chemical-intensive agriculture has also degraded soils and destroyed resources that are critical to storing carbon, such as forests and other vegetation.

The rise in use of chemical inputs has also had adverse environmental and health impacts on farm workers and consumers. A substantial portion of pesticide residues ends up in the environment, causing pollution and biodiversity decline. The extensive use of pesticides has also resulted in pesticide resistance in pests and adverse effects to beneficial natural predators and parasites [30]. The Green Revolution also brought about a shift from diversity to monocultures. When farmers opted to plant Green Revolution crop varieties and raise new breeds of livestock, many traditional, local varieties were abandoned and became extinct. And yet, maintaining agricultural biodiversity is vital to long-term food security as it is vital insurance against crop and livestock disease outbreaks and improves the long-term resilience of rural livelihoods to adverse trends or shocks [31].

In genetic engineering technology, genetically modified organisms (GMO) are created by altering the DNA of an organism, in this case a food producing plant; this is done in order to change the characteristics of the plant. Through this process of genetic engineering (GE) a plant can be made to produce a higher yield, be more resistant to pesticides, require less water and still be fast growing. The problem of food security seemed to be solved by producing plants which produce more food and are resistant to pests, so with very little testing and no real case studies and field trials, genetically engineered seeds began to be produced to grow genetically modified crops. An American company called Monsanto took the lead and became the largest producer of GM seeds as well as their famous herbicide called 'Roundup'. Monsanto made the winning combination; a very successful weed killer and their GM seeds, which are tolerant to their herbicide [32]. A lot of food that we eat today contains genetically modified ingredients and usually without our knowledge. Supporters of this technology maintain that it ensures and sustains food security around the world as the population increases. However, a debate on the socioeconomic ramifications of the way such science is marketed and used continues. Critics believe that the problem of food shortages is a political and economic problem, food shortages and hunger are and will be experienced by the poorer nations and that GE Food is an expensive technology that the farmers of the developing nations would not be able to afford easily.

Substantial improvements are possible in rain-fed agriculture, particularly in sub-Saharan Africa and South Asia. Tapping this potential requires innovative strategies to manage the sudden excesses of water and frequent dry spells. Integrating soil and water management focused on soil fertility, improved rainfall infiltration, and water harvesting can significantly reduce water losses, and improve yields and water productivity. Water storage has the greatest potential to deliver more water for food. Apart from dams, storage can also mean holding 
water in natural wetlands and reservoirs, in groundwater aquifers, soils, and in small tanks and ponds. Modern irrigation technologies, such as sprinkler and micro irrigation, have potential for adaptation to smallholdings; particularly where farmers are growing high-value marketable crops and where water is scarce. Affordable systems, such as bucket and drum drip irrigation kits, have been developed for small plots and vegetable gardens predominantly cultivated by women. The introduction of treadle pumps, originally developed in Bangladesh, has revolutionized water lifting [33].

Conservation agriculture technology on the other hand is a farming practice being piloted in Kenya by the government. The method contributes to sustainable agricultural production and environmental conservation, by maintaining a permanent or semi-permanent organic soil cover; through the use of mulches or cover crops, employment of zero or minimum tillage and crop rotation. Weed control is done using herbicides or shallow cultivation resulting to minimal soil disturbance, water and nutrients retention. Some of the benefits of conservation agriculture technology are reduced labor and farm-power requirements, improved soil fertility, crop yields increase over time compared to conventional farming, livelihood improvement, decreased carbon dioxide in the atmosphere and reduction of climate change.

Conservation agriculture technology acknowledges the importance of creating and maintaining a healthy soil and integrates various approaches to the management of weeds, pests, diseases, and plant nutrients. Adoption of conservation agriculture technology will help crops adapt to changing climatic conditions and ensure harvest despite unreliable rainfall. This is an innovation whose time has come and cannot be stopped.

\section{Adopting evidence based Innovative technology for environmental sustainability}

There is need for countries and communities to adopt research based innovations that have proved effective in addressing food insecurity and environmental sustainability. The following are some of the examples;

Integrated pest management: The aim is to produce quality crop yields with techniques that minimize environmental impacts. Pest outbreaks can thus be prevented or limited, by developing and using green mechanical, biological, chemical and other controls only as needed.

Fertilizers: The use of fertilizers helps increase cultivated soil carbon reserves by increasing the photosynthetic conversion of $\mathrm{CO}_{2}$ to biomass that is subsequently converted to soil organic matter.

Water management: Agriculture depends on water availability and water quality, thus it will be increasingly important to develop innovative strategies for sustainable water management. Innovative methods for conserving water on the farm-level will be important, such as improved irrigation techniques and indigenous furrow/pans irrigation. 
Improved seeds: Where appropriate, improved seeds, including those derived through biotechnology, have the potential to make a major contribution to increasing crop yields, nutritional content, and productivity, and mitigating environmental impacts such as climate change. Drought-tolerant crop varieties, for example, have the ability to help protect yield potential when water is scarce, while other crop varieties can be produced with genetics that protect against yield losses due to flood conditions. Salt-tolerant crops can be developed to allow land that has become unproductive for crops to be used for food production. Breeding of plants with improved water efficiency will be important. Plants with an improved nitrogen-efficiency can grow and produce high yields with lower amounts of fertiliser or have much higher yields under the same fertiliser input. Such plants would also help to minimise the emission of nitrous greenhouse gases (GHG) and save energy on the production of nitrogen fertiliser an energy intensive process [34].

Reduction of GHG from livestock: Livestock waste products are a source of GHG emissions. There are a number of examples of how best practices can help reduce emissions. For instance, research to reduce GHG from livestock is looking at selective breeding and biological means of reducing emissions. Examples include biogas production from animal waste by using codigestion.

Using information technology (IT) for agriculture development: Cell phones offer a means of providing valuable information and advice to farmers in remote places. IT applications in agriculture are limited in the developing countries thus there is significant potential for maximising gains in agriculture through various IT applications, such as drought and flood management coupled with climate and weather information, waste reduction, risk mitigation and market development. Local operators of ICT can search for answers in a central database and provide information on either crop prices, weather forecasts for irrigation, water management and plant diseases. Therefore, it is critical to build capacity among farmers and create conditions that would allow them to access and apply these IT applications.

Minimizing harvest losses: The reduction in pre and post harvest losses would in itself contribute in a major way to food security. There is an urgent need for replacing the rudimentary pre and post-harvest practices with innovative, scientific and low cost models.

Adjustment in farm practices: Farm mechanization will be essential for increasing food production in developing countries. Machinery and implements have to be tailor made to the conditions in each of the agro-climate zones. In addition, the development of prediction tool models and on-site diagnostics can optimize farm practices by minimizing the inputs (fertilizer, water, agrochemicals) and maximizing the yield.

Carbon Sequestration: The process of transferring atmospheric $\mathrm{CO}_{2}$ into soil and biotic pools can enhance soil quality, increase agronomic productivity, improve quality of natural waters, and lower rates of anoxia (decrease in the level of oxygen) or hypoxia (dead water) in coastal ecosystems.

Conservation agriculture: Conservation agriculture techniques such as low or no-till agriculture, made possible through the use of herbicides and biotechnology-derived crops, prevents wind and water erosion and loss of ground moisture, improves soil biodiversity, increases soil 
fertility, and in appropriate, carefully managed cases has the potential to reduce carbon emissions. In addition, by limiting soil disturbance and promoting a permanent soil cover, conservation agriculture can contribute to limiting emissions from agriculture by increasing soil carbon content (i.e. reducing emissions) and preventing erosion.

Enzyme applications: The number of enzyme applications in food applications has been growing. Enzyme technologies can improve the quality and quantity of food products. Some examples include reducing the content of unsaturated fat in fat spreads, improving vegetable flavour, increasing cheese yield, improving phosphorous use by certain animals, enhancing fiber digestion, and slowing the staling of baked goods [34].

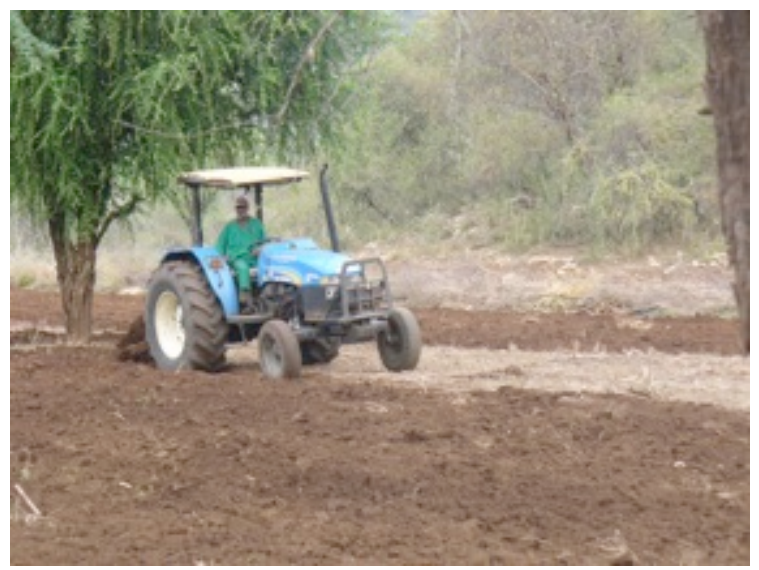

Figure 4. The photo shows adaptive agricultural mechanization in the Kerio Valley Region of Kenya, 2012

A low-carbon economy would be beneficial to the world. Research, development and deployment of clean technologies would be the most appropriate for the present and future generations not only in food production and distribution but also in all spheres of development. Governments need to encourage this innovation by all players with strong investment frameworks to harness the power of markets and stimulate research, development and deployment. A mechanism to accelerate technology development and transferring support of countries' action on adaptation and mitigation was established at the United Nations climate change talks in Cancun (2010). The mechanism was to be guided by countries' most urgent needs, priorities and national circumstances. They also provided direct in-country advice and support to facilitate prompt action on the deployment of technologies based on identified needs, including through a network of national, regional and international technology centres, networks and organizations. While developed countries have a responsibility to support developing countries to acquire clean technologies, it is important to recognize that new technologies come from all over the world. 


\section{Conclusion}

This study analysed the importance of integrating indigenous knowledge systems and modern science based agricultural technologies to attain a food secure population in the face of climate change hence securing livelihoods and environmental sustainability. The study has shown that it is important to approach food security issues and climatic changes in a multi-faceted approach. The paper argues for an explicit recognition of a hybrid evidence based approach which recognizes the need for the integration of traditional food systems, modern food systems and technologies globally. To address global food insecurity, there is a need for countries to adopt protocols and treaties pertaining to climate change mitigation. There is also a need to translate the available knowledge on climate change mitigation into action through design and implementation of evidence based interventions. Countries are encouraged to implement environmental sustainability best practices that include low carbon emission energy technologies and promote the use of energy efficient processes. Capacity building and awareness of the interrelationship of intricate chemical, physical and biological systems should be enhanced to ensure that communication about climate change and food security is meaningful. This allows people to make informed and responsible decisions towards sustainable food security and environment.

Diversification of livelihoods, adaptation of agricultural technologies, enhancing early warning systems, drought monitoring and seasonal forecasts with respect to food security is important. Improved management of cultivated land and livestock management, the use of new, more energy-efficient technologies by agro-industries and protection of ecosystems are also necessary actions towards sustainable use of the environment for food security

The main challenge to the adoption of an integrated approach is the fact that traditional knowledge exists within diverse communities with diverse traditions and most of it is not documented. Access to such knowledge is limited and therefore more research is necessary to document traditional knowledge for effective utilization in a future hybrid system. Adopting modern technologies is expensive and the process of integrating technologies requires experts who will be supported through local and community based research. The process of capturing and translating traditional knowledge into action will remain a significant challenge in most developing countries.

\section{Recommendations for further research}

- We recommend further studies on approaches to integration of indigenous knowledge systems and the science based technologies (Hybrid system) towards improved food security and environmental sustainability

- How communities can be involved in policy design, implementation and evaluation in relation to the hybrid system 
- More research on community food systems and coping strategies in face of climate change especially in most developing countries

- More research on intellectual property rights in relation to indigenous knowledge systems as related to food security and climate change.

\section{Author details}

Christopher Kipkoech Saina*, Daniel Kipkosgei Murgor and Florence A.C Murgor

*Address all correspondence to: sainachris@yahoo.com

Chepkoilel University College, School of Environmental Studies, Department of Applied Environmental Social Sciences, Eldoret, Kenya

\section{References}

[1] UNFCCC Article 1, Definitions: Accessed 12 ${ }^{\text {th }}$ August 2012 (http://unfccc.int/essential_background/convention/background/items/1349.php)

[2] IPCC Fourth Assessment Report, Working Group I, Glossary of Terms: http://ipccwg1.ucar.edu/wg1/Report/AR4WG1_Print_Annexes.pdf.

[3] EPA, 2009. EPA's Endangerment Findings Accessed 2010 June (http://www.epa.gov/ climatechange/endangerment/downloads/EndangermentFinding_ClimateChangeFacts.pdf)

[4] Mauna Loa Observatory, Hawaii. Consequences of Enhanced Greenhouse Effect Accessed 2010 June (http://www.legitimatemillions.com/globalwarming.html)

[5] NEMA 2009. State of Environmental Report Kenya, 2006/7 "Effects of Climate change and coping mechanisms in Kenya", Nairobi, Kenya

[6] IPCC (2001c) Climate change 2001: Mitigation. Contribution of working group iii to the third assessment report of the Intergovernmental Panel on Climate Change

[7] FAO. 1997. Agriculture, food and nutrition for Africa. A Resource Book for Teachers of Agriculture

[8] IPCC. 1995. Climate change: a glossary by the Intergovernmental Panel on Climate Change Accessed July, 2012 (www.ipcc.ch/pdf/glossary/ipcc-glossary.pdf).

[9] FAO (1980) Principles of Surplus Disposal and Consultative Obligations of Member Countries, Rome. 
[10] Thielke, Thilo 2006. Starvation in Africa: Kenya's Deadly Dependency on Food Aid; Accessed 2010 (http://www.spiegel.de/international/spiegel/starvation-in-africa-kenya-deadly-dependency-on-food-aid-a-396031.html)

[11] ILO. 2007. Chapter 4. Employment by sector, In Key indicators of the labour market (KILM), $5^{\text {th }}$ Edition

[12] Laurence, W.F. \& Williamson, G.B. 2001. Positive feedbacks among forest fragmentation, drought and climate change in the Amazon. Conservation Biology

[13] Gleick, P.H. 1993. Water in crisis: A guide to the world's fresh water resources. New York, Oxford University Press.

[14] Millennium Ecosystem Assessment, 2005 Accessed on 15 th August 2012 (http:// milleniumassessement.org/en/Condition.aspx)

[15] FAO. 2007. Adaptation to climate change in agriculture, forestry and fisheries: Perspective, framework and priorities. Report of the FAO Interdepartmental Working Group on Climate Change, Rome

[16] UNO, 2008. Desertification Accessed 2010. (http://www.goodplanet.info/eng/pollution/desertification/(theme)/308)

[17] UNEP (2008) Nairobi. Kenya Accessed on June, 2011 ( http://www.unep.org)

[18] UNEP, 2009. Clearing the Waters: A focus on water quality solutions Accessed in September 2010 (http://www.unep.org/PDF/Clearing_the_Waters.pdf)

[19] Seo, Sungno and Mendelsohn, Robert 2006. The impact of climate change on livestock management in africa: a structural ricardian analysis, Accessed on (http:// www.ceepa.co.za/docs/CDPNo23.pdf)

[20] IPCC Fourth Assessment Report: Climate Change 2007. Indigenous knowledge in mitigation and adaptation, Accessed on 2010 (http://www.ipcc.ch/publications_and_data/ar4/wg2/en/ch9s9-6-2-2.html)

[21] Gabriele, Geier (1995) Food Security Policy in Africa between Disaster Relief and Structural Adjustment Reflection on the Conception and Effectiveness of Policies; the Case Study of Tanzania

[22] Reeves, Tim 2009. A Sustainable Green Revolution for Global Food Security

[23] Embracing Science-Based Technologies, Accessed August 2012 (http://www.globalharvestinitiative.org/index.php/policy-center/embracing-science-based-technologies)

[24] Timmer, C.P. (1988). The agricultural transformation, In: H. Chenery and T. Srinivasan (eds), Handbook of Development Economics, Vol. 1

[25] Oniang'o, Ruth, Allotey, Joseph And Malaba, Serah 2006. Contribution of indigenous knowledge and practices in food technology to the attainment of food security in Af- 
rica - In Journal of Food Science, Vol 69 Issue 3 Accessed on August 2012 (http://onlinelibrary.wiley.com/doi/10.1111/j.1365-2621.2004.tb13346.x/pdf).

[26] Katz HS, Weaver WW. 2003. Encyclopedia of food culture Volume 1.

[27] RANDFORUM/UNDP. 1995. Sourcebook on African Food Technology. Production and Processing Technologies for Commercialization

[28] Rosset, P., Collins, J. and Lappe, F.M. 2000. Lessons from the Green Revolution: Do we need new technology to end hunger? Tikkun Magazine Vol.15, No.2

[29] Bellarby, J. et al. 2008. Cool farming: Climate impacts of agriculture and mitigation potential.

[30] Pimentel, D. 2005. Environmental and economic costs of the application of pesticides primarily in the United States, In Environment, Development and Sustainability 7: 229-252.

[31] Pimbert, M. 1999. Sustaining the multiple functions of agricultural biodiversity: FAO background paper series of the Conference on the Multifunctional Character of Agriculture and Land, 1999 FAO

[32] Taylor, Yvette 2011. Food Security and GMO Foods Accessed on may, 2012 (http:// www.earthorganization.org/articles/Library/Food_Security_and_GMO_Foods/ default.aspx)

[33] Kay, Melvin 2011. Water Smart: The role of water and technology in food security, Accessed August 2012 (http://www.intracen.org/Water-Smart-The-role-of-waterand-technology-in-food-security/)

[34] BIAC, 2009. Innovation to Address Food Security accessed on June 2012 (http:// www.biac.org/statements/agr/FIN09-11_Agriculture_and_Innovation.pdf) 
